\title{
Ku80 gene knockdown by the CRISPR/Cas9 technique affects the biological functions of human thyroid carcinoma cells
}

\author{
YALI FAN ${ }^{1,2^{*}},{\text { JIANYING } \text { LI }^{1 *}, \text { WEI WEI }}^{3}$, HANGRONG FANG $^{3}$, YING DUAN $^{3}$, \\ NAMIAO LI ${ }^{1,2}$, YINGYING ZHANG ${ }^{1,2}, \mathrm{JUN} \mathrm{YU}^{4}$ and JUANHONG WANG ${ }^{3,5}$ \\ ${ }^{1}$ Department of Respiratory Medicine, Xi'an Central Hospital, The Affiliated Hospital of Xi'an Jiaotong University, \\ Xi'an, Shaanxi 710003; ${ }^{2}$ Department of Clinical Medicine, Yan'an Medical University, Yan'an, Shaanxi 716000; \\ ${ }^{3}$ Department of Pathology, Xi'an No. 3 Hospital, The Affiliated Hospital of Northwest University, Xi'an, \\ Shaanxi 710018; Departments of ${ }^{4}$ Emergency and ${ }^{5}$ Pathology, Xi'an Central Hospital, \\ The Affiliated Hospital of Xi'an Jiaotong University, Xi'an, Shaanxi 710003, P.R. China
}

Received December 18, 2018; Accepted August 19, 2019

DOI: $10.3892 /$ or.2019.7348

\begin{abstract}
In the present study, to evaluate the role of Ku80 in thyroid carcinoma (TC), 86 thyroid tissue samples from patients with a spectrum of thyroid disorders were examined for protein levels of Ku80, nuclear factor- $\kappa \mathrm{B}(\mathrm{NF}-\kappa \mathrm{B})$ and RET/TC by immunohistochemistry. Furthermore, in TC cells, Ku80 mRNA was detected by reverse transcription-quantitative PCR analysis and silenced using the clustered regularly interspaced short palindromic repeats (CRISPR)/CRISPR-associated protein 9 (Cas9) technique to assess its role. An antibody array was used to identify Ku80-related regulatory genes. The protein levels of $\mathrm{Ku} 80$ in the TC tissues were significantly higher than those in non-neoplastic adjacent tissue samples $(\mathrm{P}<0.01)$. The activation of NF-kB and expression of RET/TC in the TC group were significantly increased $(\mathrm{P}<0.05)$ and were correlated with the protein expression of Ku80 $(\mathrm{P}<0.05)$. In papillary TC cells, the mRNA levels of Ku80 were high; Ku80 knockdown resulted in reductions in proliferation, invasion and colony formation, increased apoptosis, and reduced levels of proteins involved in MAPK signaling, cell proliferation and apoptosis. The high expression of Ku80 in TC was found to be associated with the expression of RET/TC and activation of NF- $\mathrm{KB}$, and $\mathrm{Ku} 80$ knockdown decreased the malignancy of TC cells.
\end{abstract}

Correspondence to: Dr Juanhong Wang, Department of Pathology, Xi'an No. 3 Hospital, The Affiliated Hospital of Northwest University, 10 Feng Cheng 3rd Road, Xi'an, Shaanxi 710018, P.R. China

E-mail: juanhong_wang@126.com

${ }^{*}$ Contributed equally

Abbreviations: IHC, immunohistochemistry; TC, thyroid carcinoma; NF- $\kappa B$, nuclear factor- $\kappa \mathrm{B}$; NJEJ, non-homologous end-joining; EGFP, enhanced green fluorescent protein; OD, optical density; TBS-T, TBS-Tween 20

Key words: thyroid carcinoma, Ku80, immunohistochemical, CRISPR/Cas9

\section{Introduction}

According to reports, $\sim 1-2 \%$ of all of cancer cases occur in the thyroid (1). Papillary thyroid carcinoma (PTC) is the most common malignancy of the thyroid gland. The incidence of PTC in 30-50-year-old women is twice that of age-matched men (2). The prevalence of PTC has been increasing at an alarming rate of $\sim 4 \%$ per year in the United States (3). Although patients with PTC have a good prognosis, half of patients are $<40$ years of age and more likely to develop lymph node metastasis; patients may experience recurrence or even succumb to disease. Therefore, examining the molecular mechanism underlying the occurrence and development of TC is of high significance.

$\mathrm{Ku}$ is a DNA-binding protein that is important in double-stranded DNA break repair via the non-homologous end-joining pathway $(4,5)$. It is also essential for V(D)J recombination (5). The abnormal expression of $\mathrm{Ku}$ has been reported in a variety of tumors. Ku gene mutation may result in altered DNA repair mechanisms and genomic instability. The abnormal expression of $\mathrm{Ku}$ is considered to be closely related to the occurrence and development of malignant tumors. However, related reports are not concordant and some are contradictory. For example, the expression of Ku70/Ku80 has been shown to be decreased in various types of malignant tumor, such as colon adenocarcinoma, malignant melanoma, lung cancer and cervical cancer (6), suggesting that the downregulation of $\mathrm{Ku}$ is correlated with the occurrence and development of these tumors. By contrast, the levels of $\mathrm{Ku}$ in ovarian cancer, bladder cancer, malignant lymphoma, esophageal cancer, breast cancer, non-melanomatous skin cancer, oral cancer and other tumor tissues have been shown to be elevated (6), revealing $\mathrm{Ku}$ as an oncogenic protein that can lead to tumorigenesis and development through transcriptional regulation, the inhibition of apoptosis and the induction of cell proliferation. The role of $\mathrm{Ku}$ in the occurrence and development of TC, and the underlying mechanism remain to be fully elucidated.

Previous studies have shown that the protein expression of $\mathrm{Ku}$ is altered in human tumor tissues, with $\mathrm{Ku}$ presumably 
associated with tumorigenesis; however, the specific role of $\mathrm{Ku}$ in tumor development and the underlying mechanisms remain undefined. In the present study, the expression of Ku80 and its associated molecules were assessed in TC and paracancerous tissues. Subsequently, Ku80 was knocked down to examine its effects on cell proliferation, apoptosis, invasion and other associated molecular mechanisms, which may provide a potential a therapeutic target for the early prevention and treatment of TC.

\section{Materials and methods}

Cell culture. The K1 human PTC cell line (cat. no. 92030501) was purchased from the European Collection of Authenticated Cell Cultures and the B-CPAP TC cell line (cat. no. SCSP-543) was purchased from the Library of Chinese Academy of Sciences (Shanghai, China). The two cell lines were authenticated using short tandem repeat analysis, as described in the 2012 ANSI Standard (ASN-0002) by the ATCC Standards Development Organization and by Capes-Davis et al (7). The K1 cells were cultured in Dulbecco's modified Eagle's medium supplemented with $10 \%$ fetal bovine serum/Ham's F12/MCDB105 (2:1:1; Gibco; Thermo Fisher Scientific, Inc., Waltham, MA, USA); the B-CPAP cells were maintained in RPMI 1640 (Gibco; Thermo Fisher Scientific, Inc.) supplemented with $10 \%$ fetal bovine serum (FBS, Ausbian) in a humidified incubator with $5 \% \mathrm{CO}_{2}$ at $37^{\circ} \mathrm{C}$.

Clinical tissue sample collection. TC and normal adjacent paracancerous samples from 20 patients, Hashimoto's thyroiditis (HT) specimens from 20 patients, HT with TC samples from 15 patients, and normal thyroid specimens from 18 patients were evaluated for the protein expression levels of $\mathrm{Ku} 80, \mathrm{RET} / \mathrm{TC}$ and NF- $\mathrm{B}$. These samples, derived from the depository of the Department of Pathology were histopathologically and clinically diagnosed at Xi'an Central Hospital (Shanxi, China) between January 2010 and December 2013, following the provision of written informed consent from the patients or their guardians. The Institutional Review Board of Xi'an Central Hospital approved the use of specimens in this study.

Knockdown of Ku80 using clustered regularly interspaced short palindromic repeats (CRISPR)/CRISPR-associated protein 9(Cas9) technology. CRISPR/Cas9 technology consists of the Cas9-puromycin (puro) lentivirus and single guide RNA (sgRNA)-EGFP ${ }^{\mathrm{MCS}}$ lentivirus (Fig. 7). The Cas9-puro lentivirus carries the puromycin resistance gene, and enhanced green fluorescent protein (EGFP) is present for labeling the sgRNA-EGFP ${ }^{\mathrm{MCS}}$ lentivirus (8). Three sgRNAs targeting the Ku80 gene were designed. The vectors corresponding to these lentiviruses were constructed by Shanghai GenePharma Co., Ltd. The sgRNA sequences were 5'-GTCATAAGCATA TCGAACTA-3', 5'-TCATATCAAGCATAACTATG-3' and 5'-GGTTCAGAGAAGATTCTTCA-3'. Initially, the K1 and B-CPAP cells were seeded in 6-well plates and infected with the Cas9-puro lentivirus. In order to obtain cells stably expressing Cas9, at $72 \mathrm{~h}$ post-infection, $2.0 \mu \mathrm{g} / \mathrm{ml}$ of puromycin was used for $48 \mathrm{~h}$ to kill uninfected cells, and K1-Cas9 and B-CPAP-Cas9 were generated (Fig. 1A). Subsequently, the log-phase K1-Cas9 and B-CPAP-Cas9 cells were infected with the three sgRNA-EGFP ${ }^{\mathrm{MCS}}$ lentiviral vectors, respectively. After $72 \mathrm{~h}$, EGFP was observed under an inverted fluorescence microscope (Fig. 1B). Reverse transcription-PCR was used to detect the expression levels of LV-Cas9-puro in the K1-cas9 and B-CPAP-Cas9 cells. A cruiser enzyme digestion assay was performed for Cas9-sgRNA activity assessment (Fig. 1C), as described below.

Cruiser enzyme digestion assay. The cruiser enzyme digestion assay was performed using a knockout and mutation detection kit (Shanghai Jisheng Medical Technology Co., Ltd. cat. no. MB001-100420rnx). In brief, the steps were as follows: i) Cells were collected for detection, and the sample genome was extracted using a genomic DNA extraction kit; ii) primers were designed for PCR amplification (primer design included cutting target sites and the recommended length of products was 350-500 bp); hybridized DNA products were obtained by PCR, according to the manufacturer's protocol; iii) enzyme digestion and screening of positive clones was performed; and iv) positive PCR products were detected.

Total RNA was extracted from cells using TRIzol (Shanghai Pufei Biotech Co.; cat. no. 3101-100). The reference gene was GAPDH, and the primers were designed and synthesized by Shanghai GenePharma Co., Ltd. GenePharma (Shanghai, China). The detection primer sequences are listed in Table I. The qPCR conditions were as follows: $95^{\circ} \mathrm{C}$ for $2 \mathrm{~min}$, then 35 cycles of $95^{\circ} \mathrm{C}$ for $20 \mathrm{sec}$ and $72^{\circ} \mathrm{C}$ for $30 \mathrm{sec}$, followed by a last cycle at $95^{\circ} \mathrm{C}$ for $5 \mathrm{~min}$ for denaturation of the primers. Analysis of the products was conducted by $2 \%$ agarose gel electrophoresis. The amplified fragment size of the positive reference was $493 \mathrm{bp}$, and the digested fragment size was $122 \mathrm{BP}$ and $371 \mathrm{bp}$, respectively. If the expected size of cleavage bands appeared in the experimental group, this was considered a positive clone screened by restriction enzyme digestion. The experiment was performed in duplicate in at least two independent repeats.

Immunohistochemistry (IHC). IHC was conducted on 4-mm FFPE histologic sections using mouse monoclonal anti-Ku80 (1:300, cat. no. 2753s; Cell Signaling Technology, Inc., Danvers, MA, USA), mouse monoclonal anti-RET/TC (1:250, cat. no. Sc-365943; Santa Cruz Biotechnology, Inc., Dallas, TX, USA) and mouse monoclonal anti-NF-кB P65 (1:500, cat. no. Sc-8008; Santa Cruz Biotechnology, Inc.). The HT, $\mathrm{HT}+\mathrm{TC}$, TC and normal paracancerous tissues were routinely dewaxed and hydrated, and antigen retrieval was performed according to the requirements of the manufacturers of primary antibodies. Subsequently, $1 \%$ hydrogen peroxide was added for $20 \mathrm{~min}$ to quench intrinsic peroxidase activity, and goat serum (Fuzhou Maixin Biotech Co., Ltd., Fuzhou, China) was used for $30 \mathrm{~min}$ to block nonspecific antibody binding. The slides were then incubated with primary antibodies at $37^{\circ} \mathrm{C}$ for 90 min. Following washing with PBS three times, the slides were incubated for $30 \mathrm{~min}$ with secondary antibodies at room temperature (MaxVision TM HRP-Polymer anti-mouse IHC kit; cat. no. KIT-5002; Fuzhou Maixin Biotech Co., Ltd.). Following three additional washes, DAB solution was added to the slides, which were then observed under a microscope. Ku80 was observed in the nucleus. Immunofluorescence double-labeling and laser confocal microscopy were used to 
A

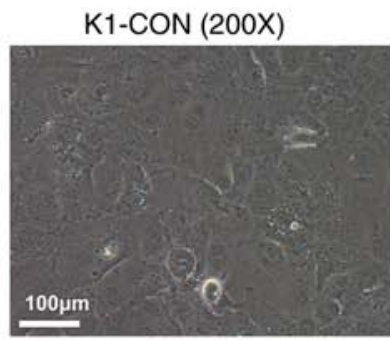

B
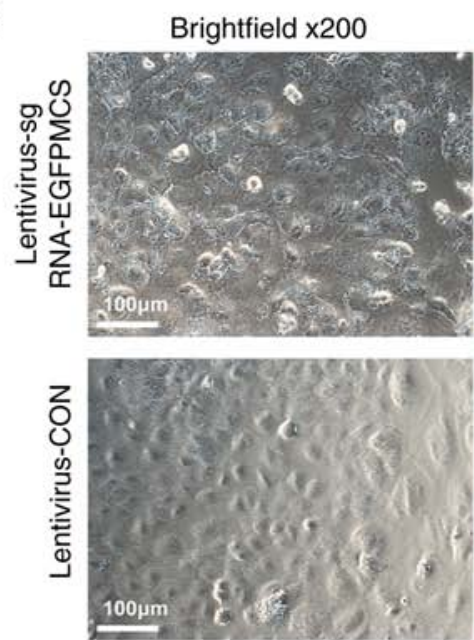

CAS9-K1

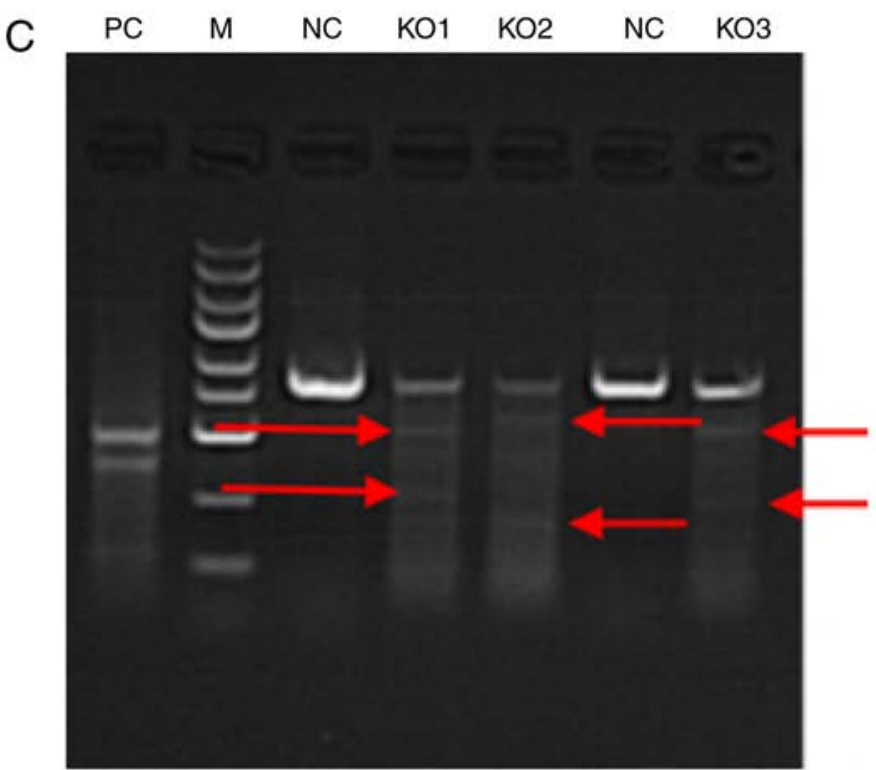

K1-cas9

K1-Cas9 (200X)

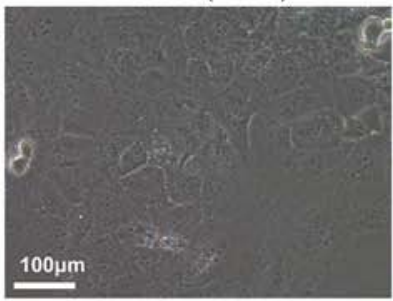

Fluorescence $\times 200$
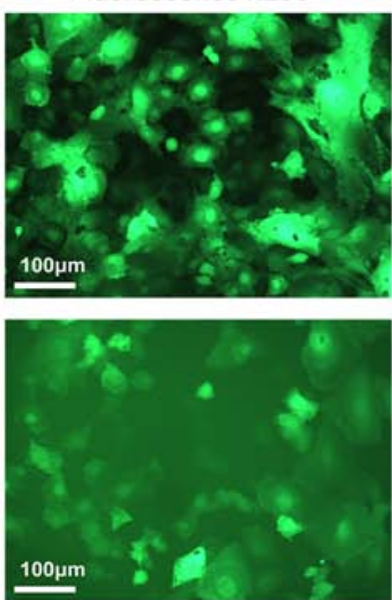

B-CPAP-CON (200X)

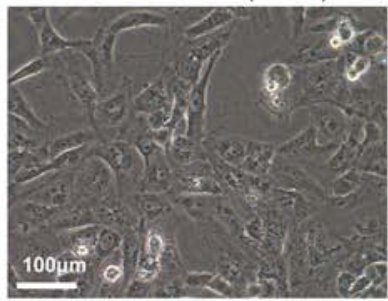

Brightfield $\times 200$
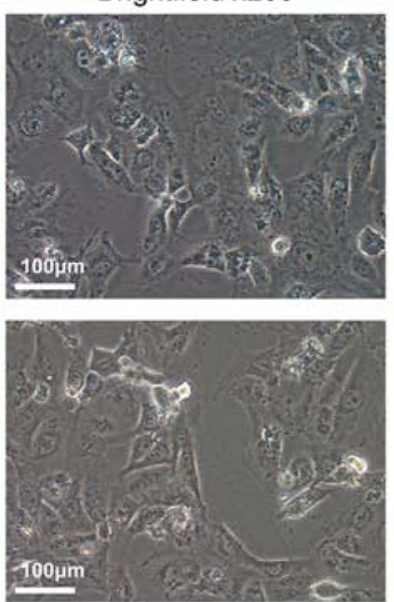

CAS9-B-CPAP

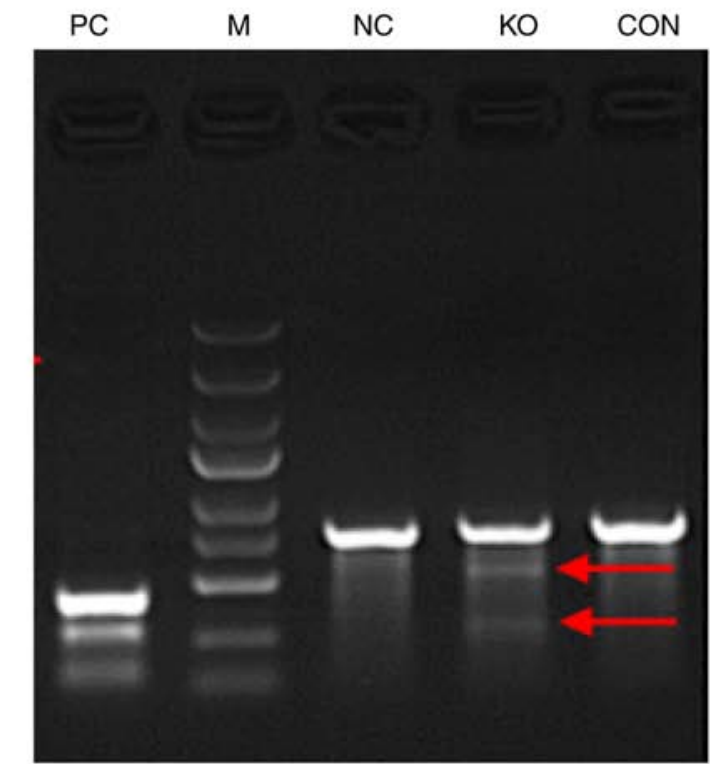

B-CPAP-cas9

B-CPAP-Cas9 (200X)

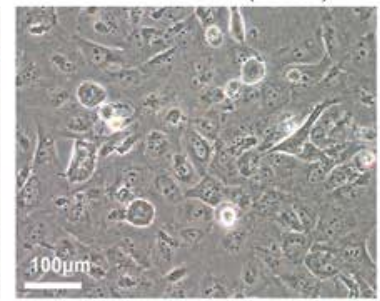

Fluorescence $\times 200$
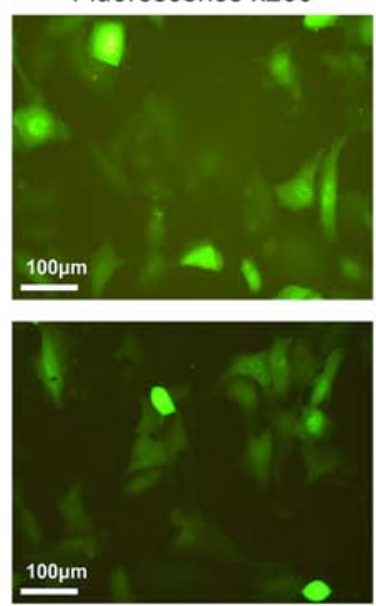

Figure 1. Microscopy and PCR results of K1 and B-CPAP cells infected with Cas9. (A) K1 and B-CPAP cells were grown and infected with the lentivirus Cas9-puro or empty virus for $16 \mathrm{~h}$ and subjected to bright field microscopy. (B) Cas9-K1 and Cas9-B-CPAP cells were infected with lentivirus-sgRNA-EGFPMCs Samples were assessed by bright field or fluorescence microscopy (magnification, x200). (C) Cruiser enzyme digestion assay for Cas9-sgRNA activity in the K1-cas9 and B-CPAP-Cas9-stably expressing strains. K1 and B-CPAP cells were successfully infected with the Cas9-sgRNA lentivirus. (KO1-3, three potential targets for Ku80 of K1 cells; KO, one potential target for the Ku80 of B-CPAP cells). Red arrows represent potential target bands of target genes. M, DL2502 ladder marker (small to large 100, 250, 500, 750, 1,000, 1,500, 2,000, 3,000 and 5,000 bp); KO, knockout; NC, negative control; CON, blank control; PC, positive reference; sgRNA, single guide RNA; EGFP, enhanced green fluorescent protein.

localize NF- $\kappa B$ and RET/TC, determining whether they were co-expressed at the cellular level. Two independent observers assessed and scored the extent of immunostaining. The ratio of stained cells and the degree of staining were used as evaluation criteria. For each case, at least 1,000 tumor cells were analyzed, and the percentage of tumor cells with positively stained nuclei was recorded. For each sample, the ratios of cells expressing Ku80, RET/TC and NF-kB P65 varied between 0 and $100 \%$, and the intensity of nuclear staining varied from weak to strong. A score was given based on 
Table I. Primers used for the Cruiser enzyme digestion assay.

\begin{tabular}{|c|c|c|c|c|c|}
\hline Target point & $\begin{array}{l}\text { Upstream sequence } \\
\qquad\left(5^{\prime}-3^{\prime}\right)\end{array}$ & $\begin{array}{c}\text { Downstream sequence } \\
\qquad\left(5^{\prime}-3^{\prime}\right)\end{array}$ & $\begin{array}{c}\text { Amplified } \\
\text { fragment } \\
\text { size (bp) }\end{array}$ & $\begin{array}{l}\text { Enzyme } \\
\text { digestion } \\
\text { fragment } 1\end{array}$ & $\begin{array}{l}\text { Enzyme } \\
\text { digestion } \\
\text { fragment } 2\end{array}$ \\
\hline KO1 (K1 cell) & $\begin{array}{l}\text { AGGTGATGGGTGA } \\
\text { CTTCAGAGG }\end{array}$ & $\begin{array}{l}\text { CCGAAAGTGTGGT } \\
\text { TCACAGACC }\end{array}$ & 801 & 528 & 273 \\
\hline KO2 (K1 cell) & $\begin{array}{l}\text { AGGTGATGGGTGA } \\
\text { CTTCAGAGG }\end{array}$ & $\begin{array}{l}\text { CCGAAAGTGTGGTT } \\
\text { CACAGACC }\end{array}$ & 801 & 597 & 204 \\
\hline KO3 (K1 cell) & $\begin{array}{l}\text { CACTGTACTACTCC } \\
\text { AAGAGCAG }\end{array}$ & $\begin{array}{l}\text { TACTTCCTTGGTC } \\
\text { TCCATGTCC }\end{array}$ & 801 & 541 & 260 \\
\hline KO (B-CPAP cell) & $\begin{array}{l}\text { AGGTGATGGGTGA } \\
\text { CTTCAGAGG }\end{array}$ & $\begin{array}{l}\text { CCGAAAGTGTGGTT } \\
\text { CACAGACC }\end{array}$ & 801 & 528 & 273 \\
\hline
\end{tabular}

Table II. Primers used in the reverse transcription-quantitative PCR analysis.

\begin{tabular}{lllr} 
Gene & \multicolumn{1}{c}{ Upstream sequence (5'-3') } & Downstream sequence (5'-3') & $\begin{array}{c}\text { Amplified fragment } \\
\text { size (bp) }\end{array}$ \\
\hline GAPDH & TGACTTCAACAGCGACACCCA & CACCCTGTTGCTGTAGCCAAA & 121 \\
XRCC5 & GCACTGACAATCCCCTTTCTG & TGTTGAGCTTCAGCTTTAACCTG & 97 \\
\hline
\end{tabular}

the percentage of positive cells: $<5 \%$ cells, 1 point; $6-35 \%$ of cells, 2 points; $36-70 \%$ of cells, 3 points; $>70 \%$ of cells, 4 points. Another score was assigned according to the intensity of staining: Negative staining, 1 point; weak staining (light yellow), 2 points; moderate staining (yellow brown), 3 points; and strong staining (brown), 4 points. The final score was calculated as the product of the above two scores. A final score $\geq 4$ indicated high protein expression in the tumor; otherwise, protein expression in the tumor was considered to be low.

Cell proliferation, colony formation, cell invasion and cell apoptosis assays. An MTT assay was used to evaluate cell proliferation. The cells were seeded at $2 \times 10^{3}$ cells per well in 96-well plates. At the end of each treatment, the cells were treated with $20 \mu \mathrm{l}$ sterile MTT $(5 \mathrm{mg} / \mathrm{ml}$, Sigma; Merck $\mathrm{KGaA}$, Darmstadt, Germany) for $4 \mathrm{~h}$ at $37^{\circ} \mathrm{C}$. The medium was then removed and $100 \mu \mathrm{l}$ of dimethyl sulfoxide (Sigma; Merck KGaA) was added. The optical density (OD) at $450 \mathrm{~nm}$ was measured on a microplate reader (Tecan Infinite, Tecan Group, Ltd., Groedig, Austria) according to the manufacturer's instructions. Data are expressed as a percentage of the control cells. The experiments were performed in triplicate. For the colony formation assay, 500 cells were seeded in each well of 6-well plates and incubated for 14 days. The colonies were fixed with $4 \%$ paraformaldehyde (Sinopharm Chemical Reagent Co. Ltd., Shanghai, China), stained with $500 \mu \mathrm{l}$ Giemsa (Shanghai Dingguo Biotechnology Co. Ltd., Shanghai, China) for $10 \mathrm{~min}$ and counted. An invasion assay was performed with Boyden chambers (Corning, Inc., NY, USA) according to the manufacturer's protocol. To assess the invasive ability of the cells, filters were precoated with Matrigel prior to cell seeding into the chambers $\left(5 \times 10^{4} /\right.$ well). The culture system consisted of a 24-well plate with 500 and $750 \mu 1$ per well in the inner and outer chambers, respectively. The cells were divided into three groups and assessed in triplicate. Following incubation at $37^{\circ} \mathrm{C}$ for $16 \mathrm{~h}$, images of the invaded cells were captured and counted under an inverted microscope. To assess apoptosis, logarithmic growth-phase cells were harvested and washed twice with PBS. Sequential staining was then performed with $10 \mu \mathrm{l}$ of Annexin V-APC with an Annexin V-APC staining kit purchased from eBioscience; Thermo Fisher Scientific, Inc. (cat. no. 88-8007). Finally, apoptosis was detected by flow cytometry according to the manufacturer's instructions (Beckman Coulter, Inc.).

$R T$ - $q P C R$ analysis. To assess gene expression levels, total RNA was isolated from the cultured cells using TRIzol (Thermo Fisher Scientific, Inc.) and reverse transcribed into cDNA with oligo (dT) primers and the M-MLV reverse transcriptase kit (Promega Corporation, Madison, WI, USA) according to the manufacturer's instructions. qPCR analysis was performed on a LightCycler 480 II Real-time PCR instrument (Roche Diagnostics, Basel, Switzerland) with SYBR Premix Ex Taq (Takara Bio, Inc., Otsu, Japan). Relative mRNA expression was determined using the human GAPDH gene as an endogenous reference standard. The qPCR conditions were as follows: An initial cycle at $95^{\circ} \mathrm{C}$ for $5 \mathrm{~min} ; 35$ cycles of $95^{\circ} \mathrm{C}$ for $50 \mathrm{sec}$ and $55^{\circ} \mathrm{C}$ for $1 \mathrm{~min}$; final extension at $72^{\circ} \mathrm{C}$ for $1 \mathrm{~min}$. The specificity of the PCR products was confirmed by melting-curve analysis. The mRNA levels of Ku80 were assessed using the $2^{-\Delta \Delta \mathrm{Cq}}$ method (9). The primer sequences used in this experiment are shown in Table II. To assess gene expression levels of $\mathrm{RET} / \mathrm{TC}$, total RNA was isolated from clinical tissue samples of the HT, HT + TC, TC and normal thyroid tissue specimens with a total RNA isolation kit (AP-MNMS-RNA; Axygen, Union City, CA, USA) as described by the manufacturer. 


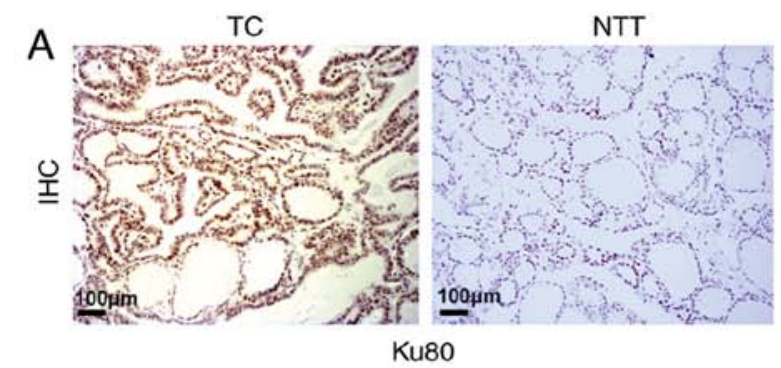

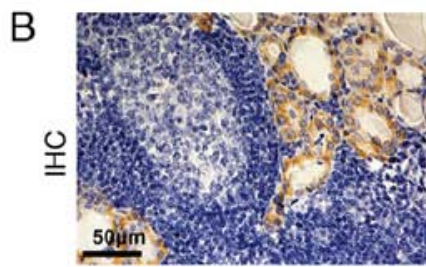

HT

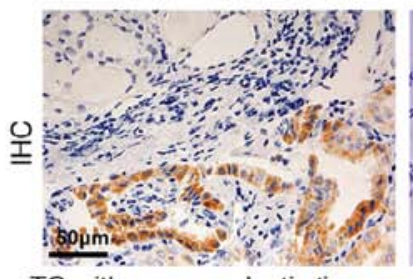

TC with paraneoplastic tissue

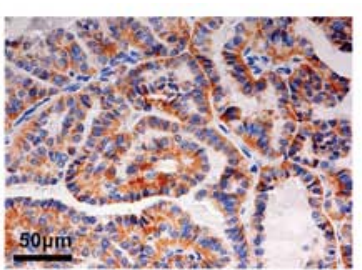

TC

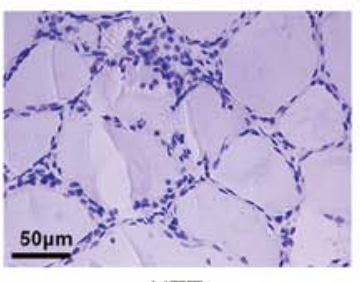

NTT

RET/TC
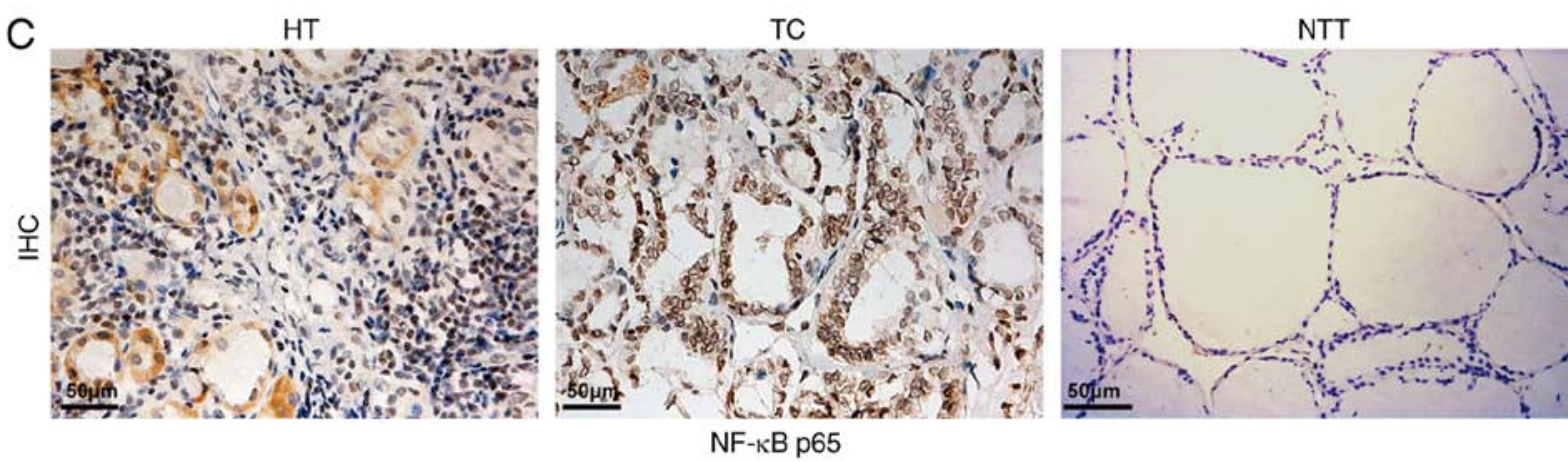

D
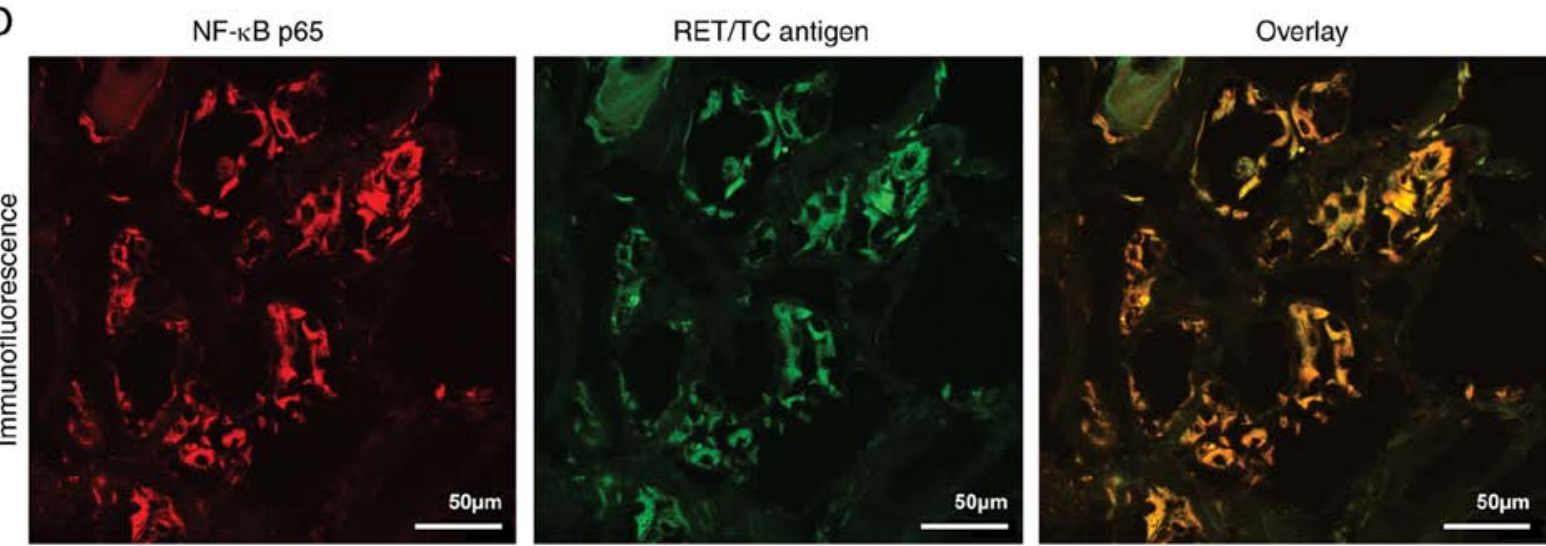

Figure 2. Ku80, RET/TC and NF- $\kappa$ B p65 expression in NTT, TC, HT and paracancerous tissues. (A) IHC staining for Ku80 assessment in TC and adjacent tissues (magnification, x100). Ku80 was expressed in TC tissues (strong positive staining of nuclei) but not in adjacent tissues (no positive staining of nuclei or cytoplasm). (B) IHC detection of RET/TC protein expression in the diseased thyroid tissue (magnification, x40). HT exhibited weak positive staining of the cytoplasm; TC exhibited strong positive staining of the cytoplasm; TC with paraneoplastic (slightly weakly positive staining of cytoplasm; NTT exhibited negative staining of the cytoplasm and nuclei. (C) Assessment of NF- $\mathrm{B}$ p65 protein expression in the diseased thyroid tissue by IHC (magnification, $\mathrm{x} 40$ ). HT exhibited weak positive cytoplasmic and nuclear staining; TC exhibited strong positive cytoplasmic and nuclear staining; NTT exhibited almost negative staining of the cytoplasm or nuclei. (D) Immunofluorescence double-labeling and laser confocal microscopy for RET/TC antigen and NF- $\kappa$ B detection (magnification, $\mathrm{x} 600)$. NF- $\mathrm{KB}$ expression is shown as red fluorescence, RET/TC antigen expression is shown as green fluorescence. Laser confocal microscopy results show NF- $\mathrm{B}$ and RET/TC were co-expressed in the cytoplasm and/or nuclei of thyroid follicular epithelial cells. TC, thyroid carcinoma; HT, Hashimoto's thyroiditis; NTT, normal thyroid tissue; IHC, immunohistochemistry; NF- $\kappa \mathrm{B}$, nuclear factor- $\kappa \mathrm{B}$.

Automatic western blot quantitative analysis system (WES). A total of $168 \mathrm{~h}$ after infection of the K1 cells with the Cas9-sgRNA lentivirus, total protein was extracted using a lysis buffer (Beyotime Institute of Biotechnology) and quantitated using a BCA protein assay kit (Beyotime Institute of Biotechnology). Equal quantities of protein $(20 \mu \mathrm{g})$ were separated by $10 \%$ sodium dodecyl sulfate-polyacrylamide gel electrophoresis and transferred onto polyvinylidene difluoride membranes. The membranes were first blocked with 5\% skim milk in TBS at room temperature for $1 \mathrm{~h}$, then incubated with rabbit anti-human Ku80 antibody (1:300; cat. no. 2753S; Cell Signaling Technology, Inc.) at $4^{\circ} \mathrm{C}$ overnight. The membranes were then washed with TBS/Tween 20 (TBS-T) and incubated with secondary antibodies (rabbit IgG from the Plonox kit; 1:10,000; cat. no. ab205718; Abcam) at room temperature for $2 \mathrm{~h}$. Following incubation, the membrane was washed with TBS-T three times $(10 \mathrm{~min}$ each). The target band was $83 \mathrm{kDa}$, and data were analyzed 
Table III. Positive rate of RET/PTC (\%) in diseased and normal thyroid tissue.

$$
\text { P-value }
$$

\begin{tabular}{lccccccccc} 
Factor & A & B & C & D & A vs. D & B vs. D & C vs. D & B vs. C & A vs. C vs. (B+C) \\
\hline Disease & HT & HT + PTC & PTC & NTT & & & & & \\
N & 20 & 15 & 20 & 18 & & & & & \\
PCR & $7(35 \%)$ & ND & $12(60 \%)$ & $0(0)$ & $0.009^{\mathrm{a}}$ & ND & $0.0001^{\mathrm{a}}$ & ND & 0.113 \\
IHC & $6(30 \%)$ & $9(60 \%)$ & $13(65 \%)$ & $0(0)$ & $0.021^{\mathrm{a}}$ & $0.0001^{\mathrm{a}}$ & $0.0001^{\mathrm{a}}$ & 0.762 & $0.019^{\mathrm{a}}$
\end{tabular}

${ }^{a} \mathrm{P}<0.05$ ( $\chi^{2}$ test or Fisher's exact test). HT, Hashimoto's thyroiditis; PTC, thyroid papillary carcinoma; NTT, normal thyroid; N, number of cases; IHC, immunohistochemistry; ND, not determined.

using Compass Software for Simple Western (version 4; ProteinSimple).

Cancer phenotype, PathScan stress and apoptosis signaling antibody array. The PathScan Antibody Array kit (Cell Signaling Technology, Inc.) was used to assess changes in key molecules of the signaling pathways in K1 cells co-infected with Cas9 and the sgRNA lentivirus, according to the manufacturer's protocol. The experiment was performed with two chips, including the cancer phenotype and the stress and apoptotic pathways. The samples were divided into negative control (NC) and experimental knockout (KO) groups, and data were evaluated by chemiluminescence imaging and gamma analysis. Each experiment was repeated three times.

Statistical analysis. Data are presented as the mean \pm standard deviation and were analyzed using SPSS 22.0 statistical software (IBM Corp., Armonk, NY, USA). Comparisons between groups for statistical significance were made using Student's t-test. (two-tailed, paired) $\mathrm{P}<0.05$ was considered to indicate a statistically significant difference.

\section{Results}

High expression of Ku80 in TC tissues and cells is associated with RET/TC rearrangement and the activation of $N F-\kappa B$. Studies have found that Ku80 gene polymorphism is associated with susceptibility to PTC (10). The fusion oncogene RET/TC, expressed in most TC cells, activates nuclear transcription factor $\mathrm{NF}-\kappa \mathrm{B}$, which regulates $\mathrm{Ku} 70$ and Ku80 (11,12). Therefore, the present study examined the expression of Ku80 in TC and paracancerous tissue samples and found significantly higher levels of Ku80 in the tumor specimens $(16 / 20,80 \%)$ compared with that in the normal samples $(4 / 20,20 \%)$ (Fig. 2A). RT-qPCR analysis showed that the levels of RET/TC were higher in HT (7/20, 35\%) and TC $(12 / 20,60 \%)$ tissues compared with those in paracancerous normal samples, in which no expression of RET/TC was detected $(\mathrm{P}<0.01)$. This indicated that $\mathrm{RET} / \mathrm{TC}$ rearrangement may occur from the early lesion of HT to TC. This finding was also confirmed by IHC in the above tissues. The expression of RET/TC in HT $(6 / 20,30 \%)$ tissues was lower than that in TC $(13 / 20,65 \%)$ tissues $(\mathrm{P}<0.01)$. This further suggested that the expression of RET/PTC in HT may occur from the early lesion
Table IV. Immunohistochemical data for $\mathrm{NF}-\kappa \mathrm{B}$ and its co-expression with the RET/TC antigen.

\begin{tabular}{lccc}
\hline \multirow{2}{*}{ Group } & \multicolumn{3}{c}{ Positive cases/total cases $(\%)$} \\
\cline { 2 - 4 } & RET antigen & NF- $\kappa \mathrm{B}$ & RET + NF- $\kappa \mathrm{B}$ \\
\hline HT & $6 / 20(30)^{\mathrm{a}}$ & $18 / 20(90)^{\mathrm{a}}$ & $6 / 20(30)$ \\
HT + TC & $9 / 15(60)^{\mathrm{a}}$ & $14 / 15(93.3)^{\mathrm{a}}$ & $9 / 15(60)$ \\
TC & $13 / 20(65)^{\mathrm{a}}$ & $19 / 20(95)^{\mathrm{a}}$ & $13 / 20(65)$ \\
NTT & $0 / 18(0)$ & $5 / 18(27.8)$ & $0 / 18(0)$ \\
\hline
\end{tabular}

${ }^{\text {a }}<<0.05$, compared with the NTT group. HT, Hashimoto's thyroiditis; TC, thyroid carcinoma; NTT, normal thyroid; NF- $\mathrm{kB}$, nuclear factor- $\mathrm{kB}$.

of HT, increasing in TC (Table III, Fig. 2B). IHC was also used to detect the expression of $\mathrm{NF}-\kappa \mathrm{B}$. Compared with that in the normal thyroid tissue, the expression of $N F-\kappa B$ in the diseased thyroid tissue was elevated, with nuclear translocation of $\mathrm{NF}-\kappa \mathrm{B}$ present in the HT $(18 / 20,90 \%)$ and TC $(19 / 20,95 \%)$ tissues with the expression of RET $(\mathrm{P}<0.01$; Fig. $2 \mathrm{C})$, indicating that $\mathrm{NF}-\kappa \mathrm{B}$ was in the active state. These findings suggested that the protein expression of RET may transform HT into TC by activating NF- $\mathrm{NB}$. To confirm this result, the co-expression of $\mathrm{NF}-\kappa \mathrm{B}$ and $\mathrm{RET} / \mathrm{TC}$ was detected by immunofluorescence double labeling and laser confocal microscopy. The results showed that NF- $\kappa \mathrm{B}$ and RET/TC were co-expressed in the HT and TC thyroid follicular epithelial cells, confirming that the protein expression of RET may transform HT into TC by activating $\mathrm{NF}-\kappa \mathrm{B}$. Representative photomicrographs are shown in Fig. 2D and the results are summarized in Table IV.

Knockdown of Ku80 suppresses TC cell proliferation, invasion and colony formation. To assess the role of Ku80 in TC cell proliferation, invasion and colony formation, the CRISPR/Cas9 technique was used to knock down Ku80 in $\mathrm{K} 1$ and B-CPAP cells. A total of $168 \mathrm{~h}$ after infection, the knockdown efficacy of Ku80 was determined by western blotting and RT-qPCR analysis, respectively. As shown in Fig. 3A, compared with the NC group, the Ku80 sgRNA-infected K1 cells exhibited a $99.3 \%$ reduction in protein levels of Ku80, indicating a high knockdown efficacy. 
A

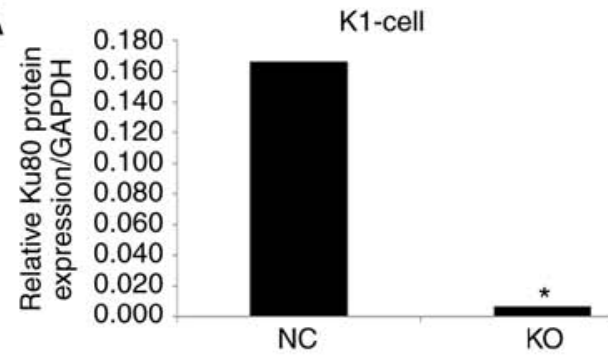

B
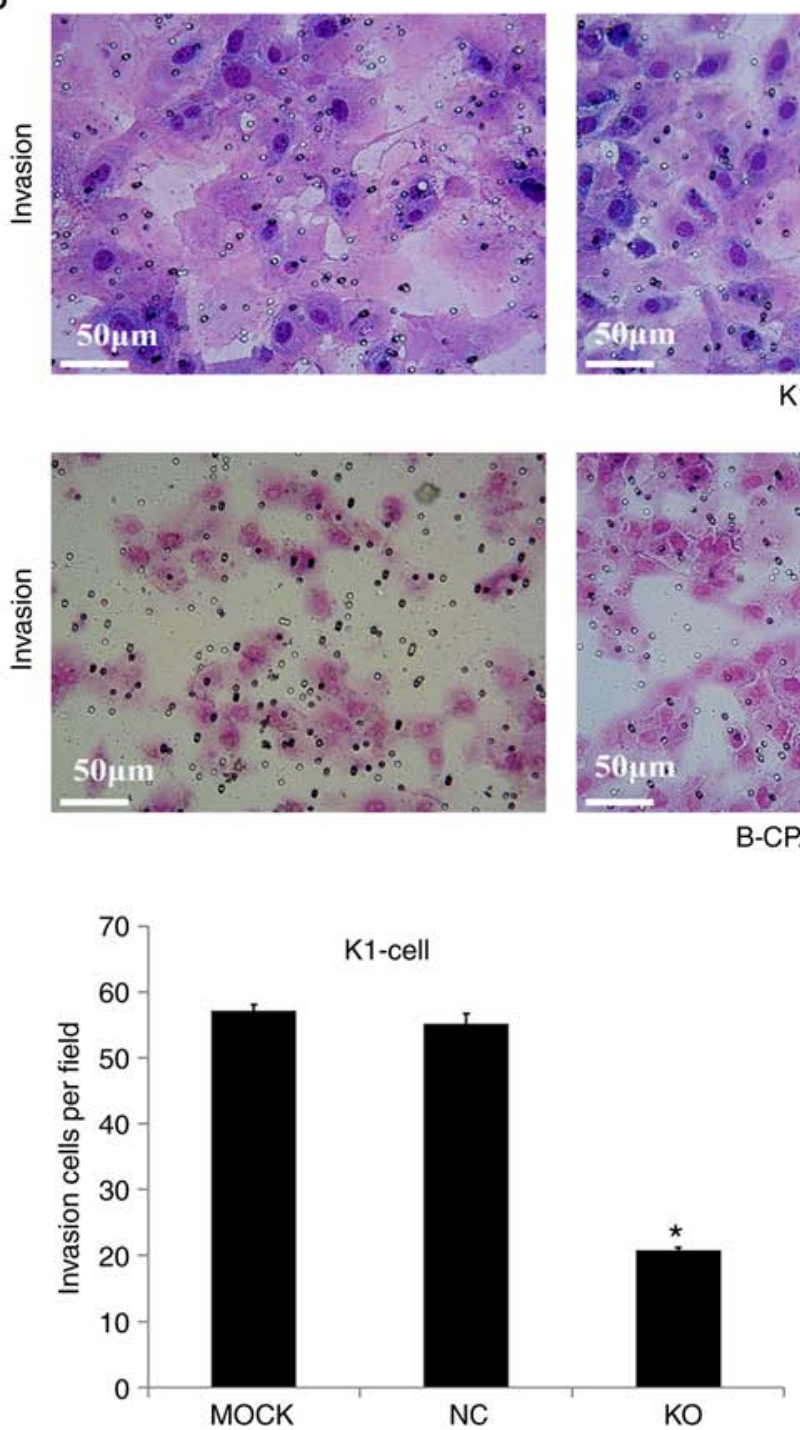
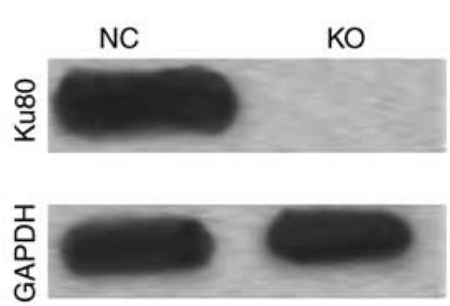

MOCK

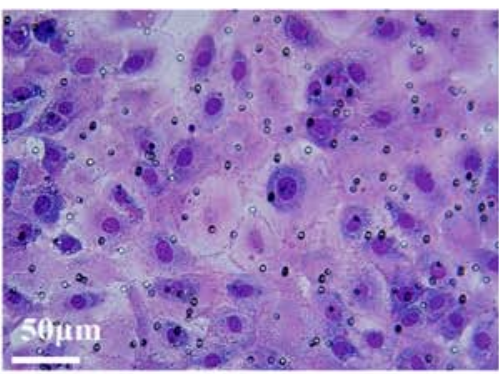

K1-cell

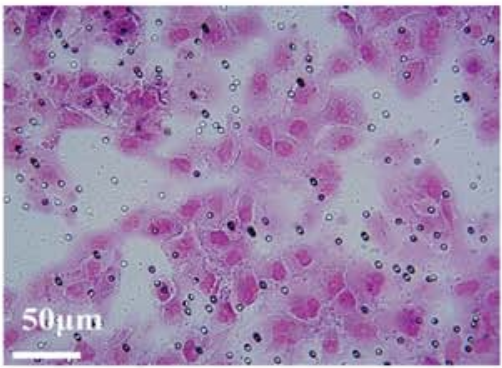

B-CPAP-cell
$1.2 \quad$ B-CPAP-cell

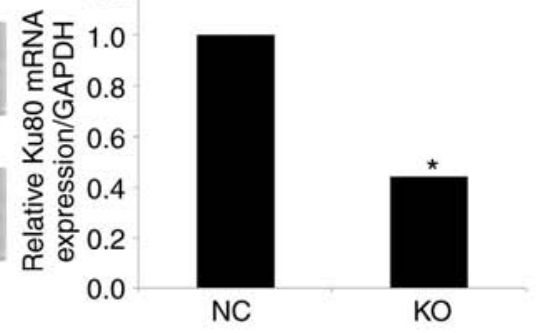

NC
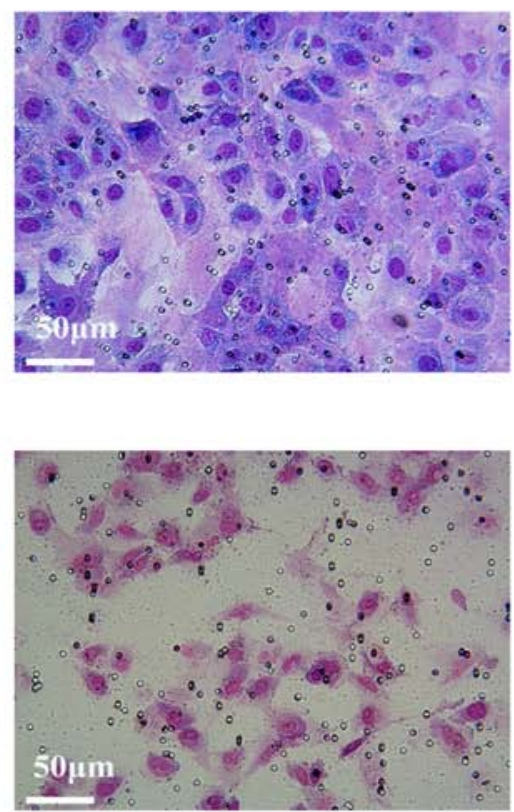

B-CPAP-cell
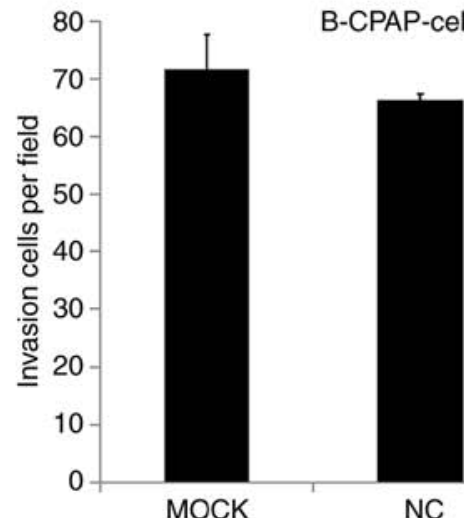

NC

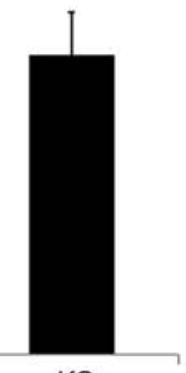

KO

Figure 3. Effect of Ku80 knockdown on TC cell invasion. (A) Expression levels of Ku80 in Cas9-sgRNA lentivirus-infected B-CPAP and Cas9-sgRNA lentivirus-infected K1 cells. Peak area analysis of Ku80 protein in K1-Cas9 cells; protein expression of Ku80 in K1-Cas9 cells, detected by western blotting; Detection of Ku80 mRNA in B-CPAP-Cas9 cells following Ku80 knockdown by quantitative PCR. (B) Effect of Ku80 knockdown on K1 and B-CPAP cell invasion. K1 and B-CPAP cells were grown and infected with the Cas9-sgRNA lentivirus for $16 \mathrm{~h}$ and subjected to an invasion assay. Transwell photomicrographs of K1-Cas9 and B-CPAP-Cas9 cells in various experimental groups are shown. The graphs show the summarized data of the invasion assay of K1 and $\mathrm{B}-\mathrm{CPAP}$ cells, respectively ( ${ }^{*} \mathrm{P}<0.05$ vs. $\mathrm{NC}$ cells). KO, experimental group; NC, negative control group; MOCK, blank control group.

In addition, RT-qPCR analysis showed that the mRNA levels of Ku80 were reduced by $56 \%$ in the Ku80 sgRNA-infected B-CPAP cells. To further evaluate the effect of Ku80 on proliferation, the proliferative ability of sgRNA-infected K1 and sgRNA-infected B-CPAP cells were then assessed using an MTT assay, which revealed that the proliferation rates of the $\mathrm{K} 1$ cells were significantly decreased on days
4 and 5 following Ku80 knockdown compared with those of the control cells $(\mathrm{P}<0.05)$. The proliferative ability of the B-CPAP cells on the fifth day did not differ significantly from that on the first day (Fig. 4A). These results were confirmed by colony formation and invasion assays; in $\mathrm{K} 1$ cells, the numbers of invasive cells and cell clones formed were markedly decreased following Ku80 knockdown 

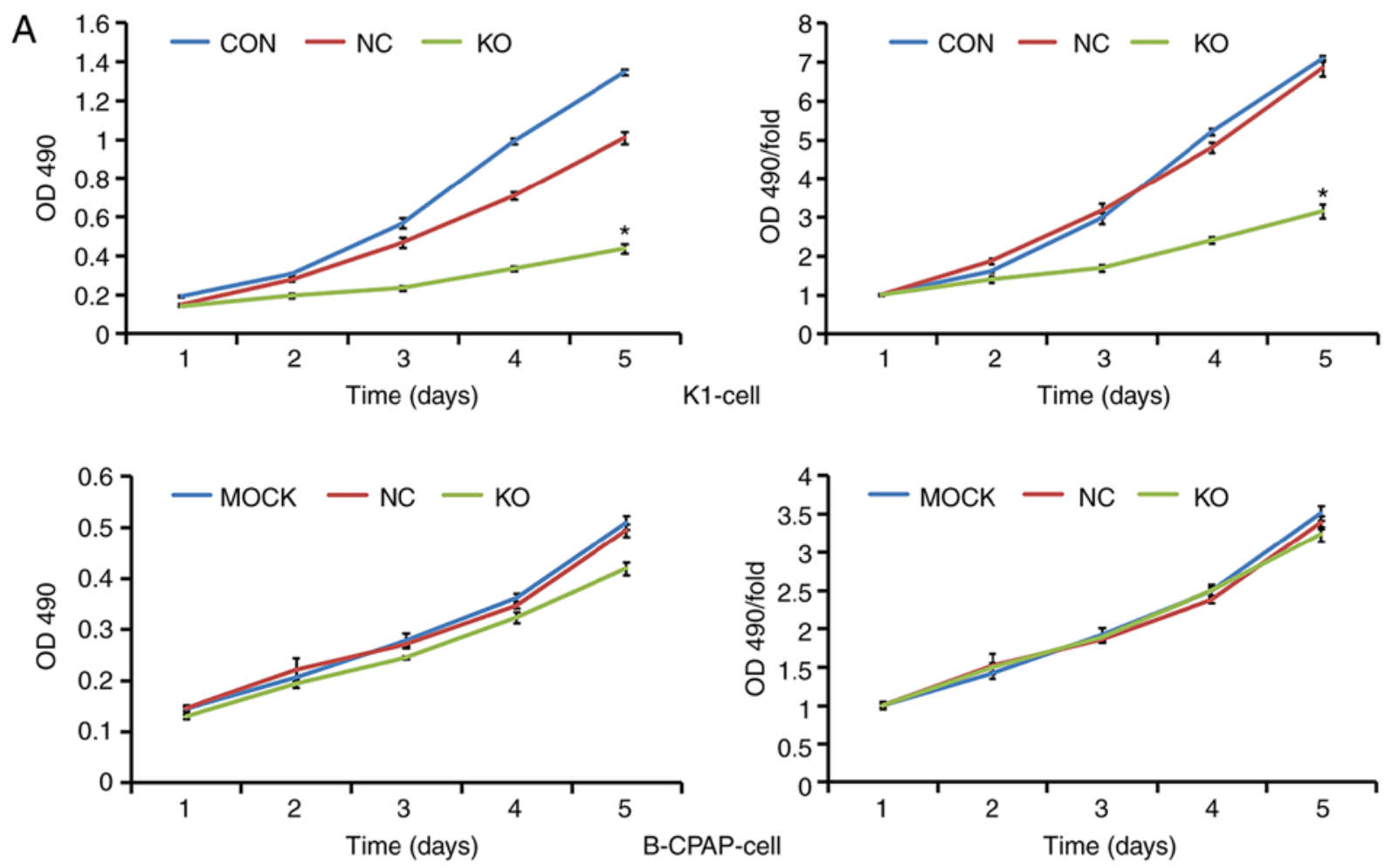

B

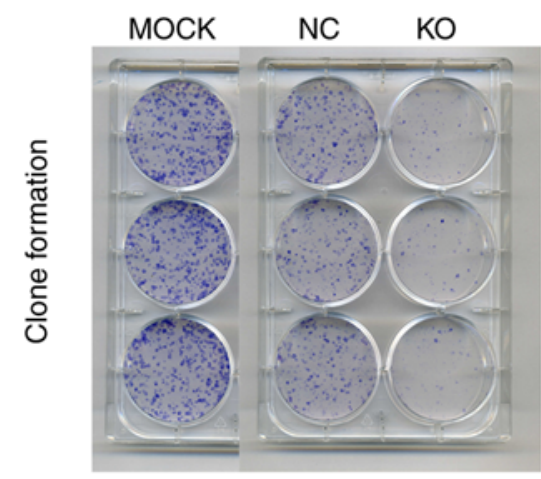

K1-cell

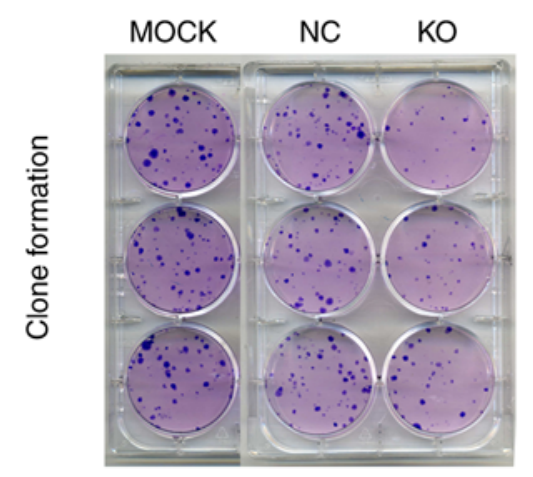

B-CPAP- cell
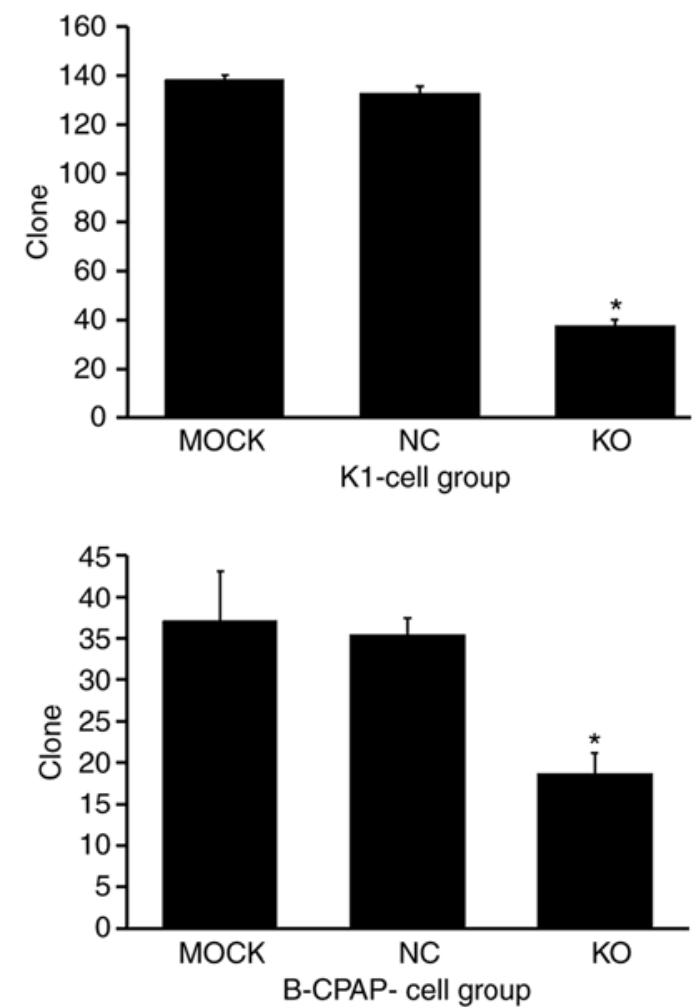

Figure 4. Effect of Ku80 knockdown on TC cell proliferation and clone formation. (A) Effect of Ku80 knockdown on K1 and B-CPAP cell proliferation. K1 and B-CPAP cells were grown and infected with the Cas9-sgRNA or control lentivirus, and subjected to an MTT assay. Proliferation and fold curves of K1 and B-CPAP cells in various experimental groups are shown. (B) Effect of Ku80 knockdown on K1 and B-CPAP cell clonal formation ability. Digital photographs of colonies formed in various experimental groups of K1-Cas9 and B-CPAP-Cas9 cells are shown with quantitation of the digital photographs on the right ( $\mathrm{P}<0.05$ vs. NC cells). KO, experimental group; NC, negative control group; MOCK, blank control group; OD, optical density.

compared with numbers in the control group. The invasive ability of the sgRNA-B-CPAP cells was not significantly decreased $(\mathrm{P}>0.05)$, however, the clone formation ability was significantly decreased $(\mathrm{P}<0.05)$ (Figs. $3 \mathrm{~B}$ and $4 \mathrm{~B})$. The proliferation and invasiveness of the sgRNA-B-CPAP cells were not decreased compared with those in the control group, possibly due to the rate of Ku80 knockdown being lower than that of the K1 cells. Collectively, these findings suggested 

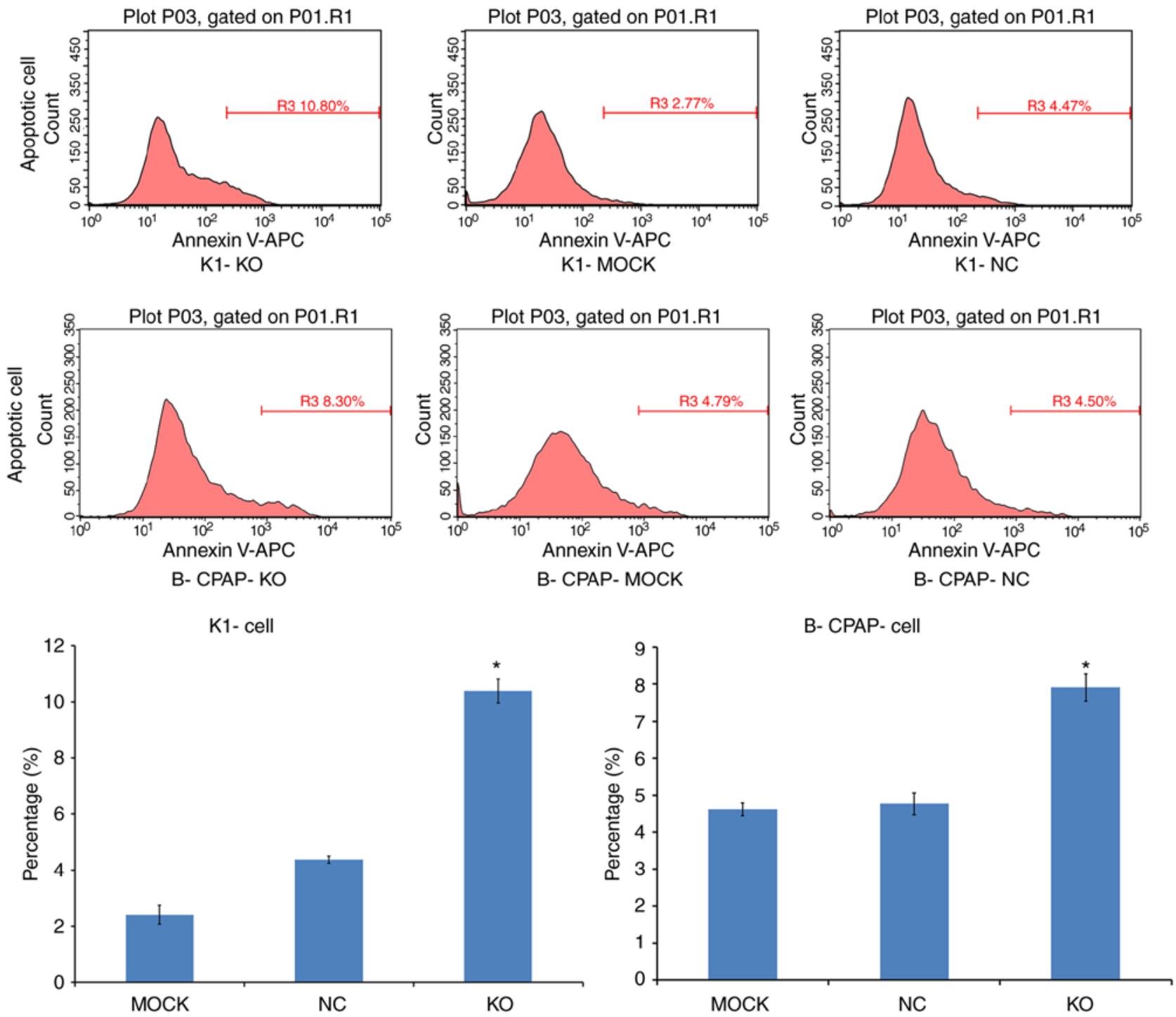

Figure 5. Effect of Ku80 knockdown on K1 and B-CPAP cell apoptosis. Peak figures of K1-Cas9 and B-CPAP-Cas9 cells in various experimental groups are shown above, with the respective quantitation shown in graphs below (" $\mathrm{P}<0.05$ vs. $\mathrm{NC}$ cells). KO, experimental group; NC, negative control group; MOCK, blank control group.

that Ku80 was important in the proliferation, invasion and colony formation of TC cells in vitro.

Knockdown of Ku80 promotes TC cell apoptosis. Apoptosis was assessed by Annexin V-APC single staining. Flow cytometric analysis demonstrated that, compared with the control, the apoptotic rates of the sgRNA-K1 cells were $4.38 \pm 0.12$ and $10.38 \pm 0.42 \%$ in the $\mathrm{NC}$ and $\mathrm{KO}$ cells, respectively. The percentages of apoptotic sgRNA-B-CPAP cells were 5.01 \pm 0.24 and $7.82 \pm 0.22 \%$ in the $\mathrm{NC}$ and $\mathrm{KO}$ groups, respectively. Both infected cell lines exhibited significantly increased apoptotic rates $(\mathrm{P}<0.05$; Fig. 5), indicating that Ku80 suppressed TC cell apoptosis.

Identification of genes mediating the activity of Ku80 in TC cells. To detect and compare key signaling molecules in K1 cells, PathScan stress and apoptosis signaling antibody array analysis was performed for $\mathrm{K} 1$ cells infected with CRISPR/Cas9 or control lentiviruses. Chemiluminescence and gray scale data indicated that, compared with the NC group, the KO group had significantly reduced protein expression levels of vimentin, CD45, proliferating cell nuclear antigen (PCNA), Ki-67, phosphorylated (p-)retinoblastoma (Rb), hypoxia-inducible factor $1 \alpha(\mathrm{HIF}-1 \alpha)$, survivin and EGF receptor in cancer phenotype pathways (Fig. 6A, $\mathrm{P}<0.05$ ). Similarly, the protein expression levels of phosphorylated (p-)ERK1/2, p-Akt, p-HSP27, p-Smad2, p-SAPK/JNK, p-TGF- $\beta$-activated kinase 1 (TAK1) and survivin (involved in apoptotic signaling pathways) were also downregulated in the KO group (Fig. 6B, $\mathrm{P}<0.05$ ). These data further indicated that Ku80 altered apoptosis by regulating multiple genes in the MAPK pathway.

\section{Discussion}

TC is the most common type of endocrine malignancy and represents the leading cause of endocrine organ cancer-related mortality. As with other types of cancer, early diagnosis of TC is important for improving patient survival rate and treatment outcomes (13). Although TC has a good prognosis, there 

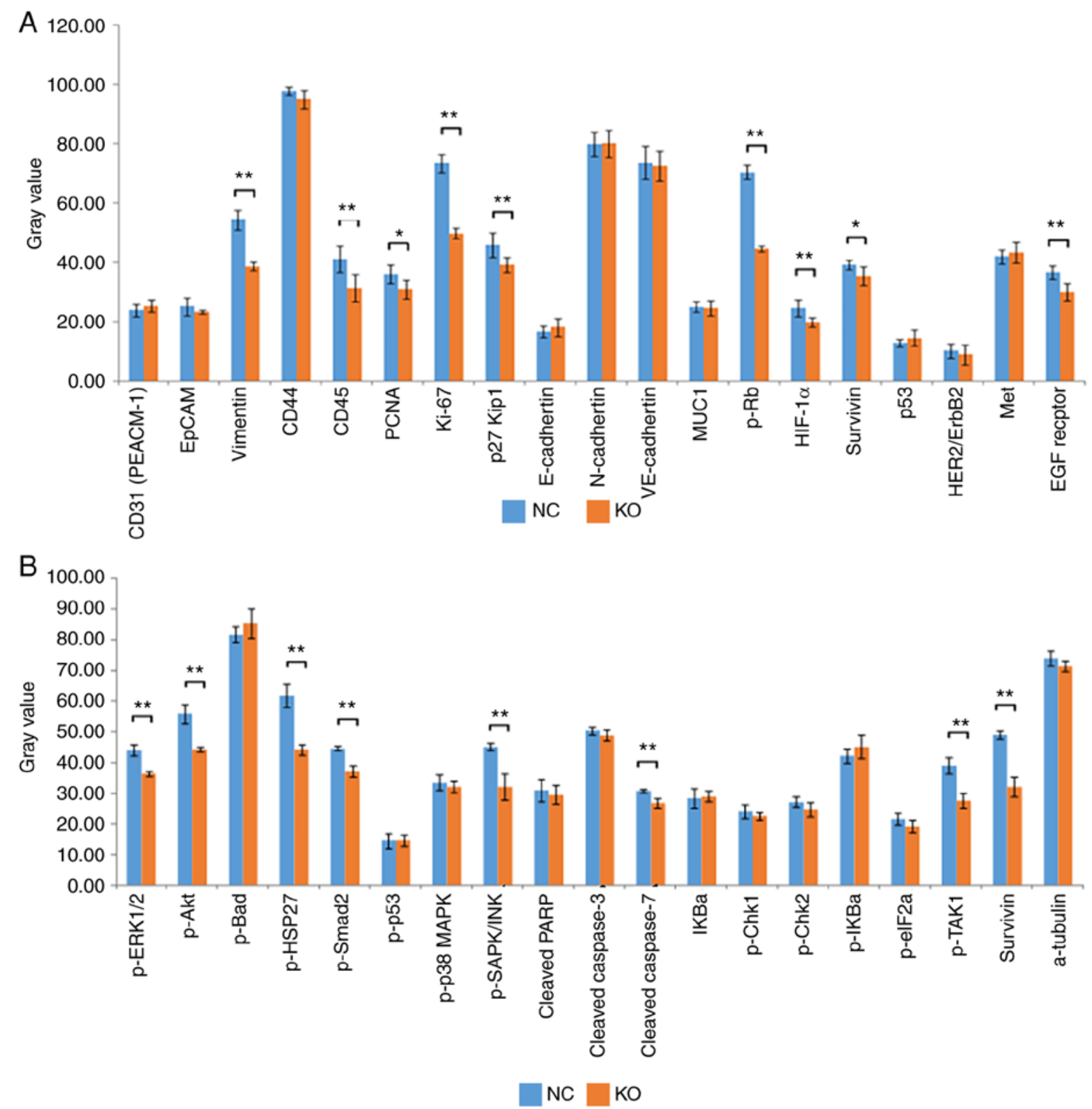

Figure 6. Identification of Ku80 knockdown-related gene expression. (A) Statistical analysis of gray values revealed that the expression levels of vimentin, CD45, PCNA, Ki-67, p-Rb, HIF-1 $\alpha$, survivin and EGF receptor in cancer phenotype pathways were significantly decreased in the KO group compared with those in the control group $\left({ }^{*} \mathrm{P}<0.05,{ }^{* *} \mathrm{P}<0.01\right)$. (B) Statistical analysis of gray values revealed that the expression levels of p-ERK1/2, p-Akt, p-HSP27, p-Smad2, p-SAPK/JNK, p-TAK1 and survivin involved in the molecular profile of stress and apoptotic signaling pathways were significantly decreased in the KO group compared with those in the control group $\left.{ }^{* *} \mathrm{P}<0.01\right)$. KO, experimental group; $\mathrm{NC}$, negative control group; $\mathrm{p}-$, phosphorylated.

is a risk of recurrence which represents a threat to human life. In recent years, the incidence of PTC has been steadily increasing worldwide (14). The etiology of PTC is most closely associated with exposure to radiation (15). Little progress has been made in mechanistic research. The present study demonstrated that the occurrence of TC is closely related to the Ku80 protein. It was found that silencing Ku80 significantly inhibited tumor cell proliferation, invasion and colony formation, and induced apoptosis. In addition, statistical analysis of gray scale values showed that the protein levels of vimentin, CD45, PCNA, Ki-67, p-Rb, HIF-1 $\alpha$, EGF receptor, p-ERK1/2, p-Akt, p-HSP27, p-Smad2, p-SAPK, JNK, p-TAK1 and survivin were significantly lower following Ku80 knockdown compared with those in the control $(\mathrm{P}<0.05)$. These findings reveal potential novel targets for TC treatment.
The $\mathrm{Ku}$ protein is the main repair protein for DNA double-strand breaks (DSBs). It is composed of Ku80 and Ku70 monomers and serves an important role in DNA DSB injury repair (16). In addition to repairing DNA DSBs, Ku has other important biological functions, including involvement in cell cycle regulation, transcriptional regulation, immunoglobulin-encoding gene V(D)J chain rearrangement and maintenance of telomere structural stability (17). Studies have shown that the protein expression of $\mathrm{Ku} 70 / \mathrm{Ku} 80$ is increased in various tumors, including ovarian cancer, bladder cancer, colon cancer, cervical cancer, malignant lymphoma, esophageal cancer, lung cancer, breast cancer, non-melanomatous skin cancer and cancer of the oral cavity (6), revealing $\mathrm{Ku}$ as an oncogenic protein. The increased activity of $\mathrm{Ku}$ inhibits apoptosis and promotes cell proliferation through transcriptional 


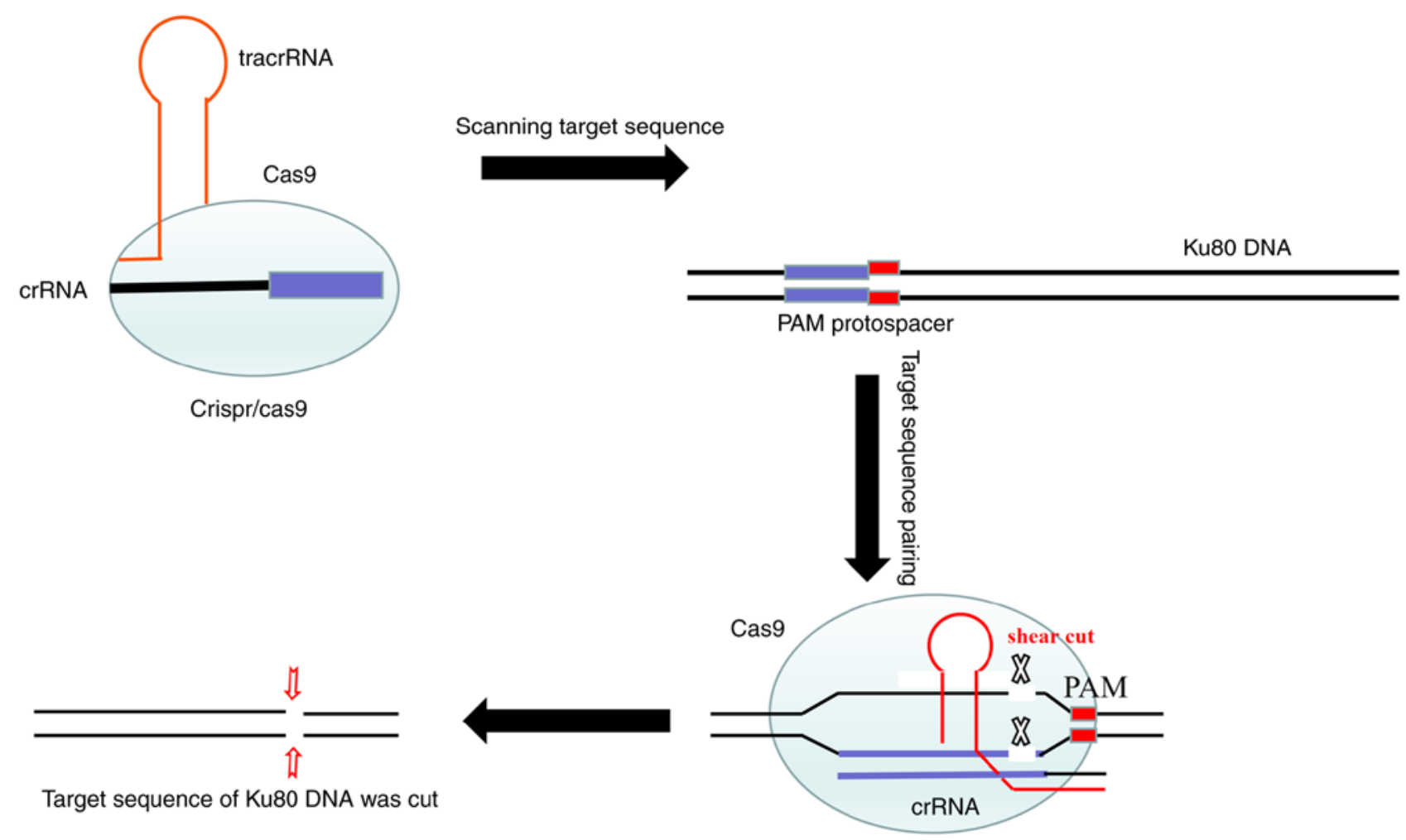

Figure 7. Schematic diagram of CRISPR/Cas9. The CRISPR/Cas9 dual-vector lentivirus knocked out the target sequence of the Ku80 gene. CRISPR, clustered regularly interspaced short palindromic repeats; Cas9, CRISPR-associated protein 9; tracrRNA, trans-activating RNA; crRNA, CRISPR-derived RNA; PAM, proto-spacer adjacent motifs.

regulation, leading to tumorigenesis and cancer development. However, the mechanisms underlying the effects of $\mathrm{Ku}$ in $\mathrm{TC}$ have rarely been reported. In order to clarify the association between $\mathrm{Ku}$ and $\mathrm{TC}$, the present study analyzed the level of $\mathrm{Ku}$ in human TC tissue specimens and TC cells. As shown above, compared with the control groups, tumor samples and cells showed significantly increased expression of Ku80, corroborating previous reports. To further determine the specific role of Ku80, a series of experiments were performed following Ku80 silencing. Ku80 knockdown resulted in reduced proliferation, invasion and colony formation in tumor cells, whereas apoptosis was induced. Although the proliferative activity and invasion rate of B-CPAP cells in the MTT and invasion assays, respectively, did not differ significantly to those in the respective control groups, the overall trends of cell proliferation and invasion were downward. This suggests that the expression of Ku80, encoded by the XRCC5 gene, is extremely high in tumor cells, and the Ku80-knockdown efficiency in B-CPAP cells was not high enough, causing residual $\mathrm{Ku} 80$ to exert effects. In addition, following Ku80 knockdown, the protein expression levels of vimentin, CD45, PCNA, Ki-67, p-Rb, HIF-1 $\alpha$, EGF receptor, p-ERK1/2, p-Akt, p-HSP27, p-Smad2, p-SAPK/JNK, p-TAK1, survivin and others, which promote cell proliferation, metastasis, invasion and angiogenesis, were significantly reduced. This further demonstrates that Ku80 serves a critical role in the development of TC.

Cancer occurrence is a complex process. The mutation or ectopicity of related genes in a pathway can lead to the proliferation or apoptosis of tumor cells. Common mutations include those in BRAF, RET, RAS, PTEN and RET/PTC (18). The
RET proto-oncogene, located on the long arm of chromosome 10 (10q11.2), encodes a $150-\mathrm{kD}$ receptor tyrosine kinase that was discovered in 1985 in experiments involving lymphoma DNA extracts; transfection into NIH3T3 mouse fibroblast cells results in malignant transformation $(19,20)$. Subsequent analysis of human tumors has revealed that the RET/TC fusion protein is a characteristic alteration found in $\sim 20 \%$ of patients with PTC (21). Oncogenes of the RET/PTC family, particularly $\mathrm{RET} / \mathrm{PTC1}$ and RET/PTC3, serve key roles in the development of several PTCs, particularly pediatric PTC and those resulting from exposure to ionizing radiation (22). The low RET/PTC oncogene expression observed in certain benign thyroid diseases suggests that the local cellular microenvironment may be important in regulating RET/PTC oncogenic activity. Based on previous reports, the present study assessed the gene expression levels of RET/TC remodeling in TC, normal and HT tissues by RT-qPCR and IHC analyses. Compared with levels in the normal control group, the HT and TC samples had significantly higher expression levels of RET/TC. However, its expression was lower in HT samples than that in TC samples, suggesting that the protein expression of RET in HT may be an early precursor of TC, and may be involved in the subsequent development of TC.

$\mathrm{NF}-\kappa \mathrm{B}$ consists of heterodimers of various members of the Rel family, including p50, c-Rel, v-rel, p52, p-65 (RelA) and Rel B (23). It is constitutively activated in several types of cancer $(24,25)$. As NF- $\kappa \mathrm{B}$ regulates numerous genes associated with cell transformation, survival, proliferation, invasion, metastasis and inflammation, the constitutive activation of $\mathrm{NF}-\kappa \mathrm{B}$ in cancer cells is key in various aspects of tumor 
progression (26). Numerous genes necessary for tumor growth have NF- $\mathrm{NB}$-binding sites and are targeted by this transcription factor (27). The present study found that, compared with levels in normal thyroid tissues, the expression levels of $\mathrm{NF}-\kappa \mathrm{B}$ in the diseased thyroid tissues were elevated, with RET protein expression observed in $\mathrm{HT}$ and $\mathrm{TC}$ tissues. In addition, $\mathrm{NF}-\kappa \mathrm{B}$ was found to undergo nuclear transcription and activation in TC cells, suggesting that the protein expression of RET may cause HT cancer to develop into TC by activating NF- $\kappa \mathrm{B}$.

In conclusion, the present study demonstrated that the expression of Ku80 was significantly increased in TC, which exhibited high expression levels of RET/TC and NF-KB. In addition, the expression of $\mathrm{Ku} 80$ was shown to be positively correlated with the levels of RET/TC and NF-KB. Furthermore, Ku80 knockdown significantly reduced proliferation, invasion and tumor formation in TC cells, and markedly increased the apoptotic rate. It was also shown that $\mathrm{Ku} 80$ is involved in the pathogenesis of TC. Finally, Ku80 knockdown significantly downregulated MAPK signaling pathway-related molecules in addition to proliferation and metastasis-associated proteins, including EGFR, p-ERK1/2, p-SAPK/JNK, p-Akt, p-TAK1, PCNA, Ki-67, p-Rb, HIF-1a, survivin, vimentin, CD45, p-HSP27 and p-Smad2. These findings suggest that the increased expression of $\mathrm{Ku} 80$ is closely related to the occurrence and development of TC. Upregulating Ku80 modulates the transcription of a variety of genes which promote cell proliferation, invasion and tumor formation, and inhibit apoptosis via the MAPK pathway. The present study provides a theoretical basis for TC targeted therapy. However, the work was limited by the absence of mechanistic investigation; screening for possible molecules was only performed through gene chip technology and the results were not confirmed. Further investigation is required to determine which molecules regulate the function of $\mathrm{Ku} 80$.

\section{Acknowledgements}

Not applicable.

\section{Funding}

This study was supported by the National Natural Science Foundation of China (grant no. 81372857), the Science and Technology Research and Development Program of Shaanxi Province (grant no. 2008K09-09), the Xi'an Science and Technology Program [grant no. SF09027(9)] and the Xi'an Science and Technology Program [grant no. 2016047SF/YX039(3)].

\section{Availability of data and materials}

The datasets used and/or analyzed in the present study are available from the corresponding author upon reasonable request.

\section{Authors' contributions}

YF and JL performed the experiments, participated in data collection and drafted the manuscript. WW, HF, YD and NL performed the statistical analysis and participated in study design. YZ, JY and JW helped draft the manuscript. All authors read and approved the final manuscript.

\section{Ethics approval and consent to participate}

The study protocol was approved by the Ethics Committees of Xi'an Central Hospital (LP2018-08-27).

\section{Patient consent for publication}

Not applicable.

\section{Competing interests}

The authors declare that they have no competing interests.

\section{References}

1. Liu S, Semenciw R, Ugnat AM and Mao Y: Increasing thyroid cancer incidence in Canada, 1970-1996: time trends and age-period-cohort effects. Br J Cancer 85: 1335-1339, 2001.

2. Homayouni M, Mohammad Arabzadeh SA, Nili F, Razi F and Amoli MM: Evaluation of the presence of Epstein-Barr virus (EBV) in Iranian patients with thyroid papillary carcinoma. Pathol Res Pract 213: 854-856, 2017.

3. Haugen BR, Alexander EK, Bible KC, Doherty GM, Mandel SJ, Nikiforov YE, Pacini F, Randolph GW, Sawka AM, Schlumberger M, -: 2015 American thyroid association management guidelines for adult patients with thyroid nodules and differentiated thyroid cancer: The American thyroid association guidelines task force on thyroid nodules and differentiated thyroid cancer. Thyroid 26: 1-133, 2016.

4. Lieber MR, Ma Y, Pannicke U and Schwarz K: The mechanism of vertebrate nonhomologous DNA end joining and its role in V(D)J recombination. DNA Repair (Amst) 3: 817-826, 2004.

5. Bertinato J, Tomlinson JJ, Schild-Poulter C and Hache RJ: Evidence implicating $\mathrm{Ku}$ antigen as a structural factor in RNA polymerase II-mediated transcription. Gene 302: 53-64, 2003.

6. Gullo C, Au M, Feng G and Teoh G: The biology of Ku and its potential oncogenic role in cancer. Biochim Biophys Acta 1765: 223-234, 2006

7. Capes-Davis A, Reid YA, Kline MC, Storts DR, Strauss E, Dirks WG, Drexler HG, MacLeod RA, Sykes G, Kohara A, et al: Match criteria for human cell line authentication: Where do we draw the line? Int J Cancer 132: 2510-2519, 2013.

8. Cui H, Lan X, Lu S, Zhang F and Zhang W: Bioinformatic prediction and functional characterization of human KIAA0100 gene. J Pharm Anal 7: 10-18, 2017.

9. Livak KJ and Schmittgen TD: Analysis of relative gene expression data using real-time quantitative PCR and the 2(-Delta Delta C(T)) method. Methods 25: 402-408, 2001.

10. Gomes BC, Silva SN, Azevedo AP, Manita I, Gil OM, Ferreira TC, Limbert E, Rueff J and Gaspar JF: The role of common variants of non-homologous end-joining repair genes XRCC4, LIG4 and Ku80 in thyroid cancer risk. Oncol Rep 24: 1079-1085, 2010.

11. Neely RJ, Brose MS, Gray CM, McCorkell KA, Leibowitz JM, Ma C, Rothstein JL and May MJ: The RET/PTC3 oncogene activates classical NF- $\kappa \mathrm{B}$ by stabilizing NIK. Oncogene 30 : 87-96, 2011.

12. Lim JW, Kim $\mathrm{H}$ and $\mathrm{Kim} \mathrm{KH}$ : Expression of $\mathrm{Ku} 70$ and $\mathrm{Ku} 80$ mediated by NF-kappa B and cyclooxygenase-2 is related to proliferation of human gastric cancer cells. J Biol Chem 277: 46093-46100, 2002.

13. Erdogdu IH, Yumrutas O, Ozgur Cevik M, Bozgeyik I, Erdogdu M, Inan HM and Bagis H: Differential expression of PIWIL2 in papillary thyroid cancers. Gene 649: 8-13, 2018.

14. Stewart BW and Kleihues P (eds): World Cancer Report. IARC Press, Lyon, 2003.

15. Williams D: Radiation carcinogenesis: Lessons from Chernobyl. Oncogene 27 (Suppl 2): S9-S18, 2008.

16. Dobbs TA, Tainer JA and Lees-Miller SP: A structural model for regulation of NHEJ by DNA-PKcs autophosphorylation. DNA Repair (Amst) 9: 1307-1314, 2010. 
17. Tuteja $\mathrm{R}$ and Tuteja $\mathrm{N}$ : $\mathrm{Ku}$ autoantigen: A multifunctional DNA-binding protein. Crit Rev Biochem Mol Biol 35: 1-33, 2000.

18. Liu S, Zhang B, Zhao Y, Chen P, Ji M, Hou P and Shi B Association of BRAFV600E mutation with clinicopathological features of papillary thyroid carcinoma: A study on a Chinese population. Int J Clin Exp Pathol 7: 6922-6928, 2014.

19. Ishizaka Y, Itoh F, Tahira T, Ikeda I, Sugimura T, Tucker J, Fertitta A, Carrano AV and Nagao M: Human ret proto-oncogene mapped to chromosome 10q11.2. Oncogene 4: 1519-1521, 1989.

20. Takahashi M, Ritz J and Cooper GM: Activation of a novel human transforming gene, ret, by DNA rearrangement. Cell 42 : 581-588, 1985.

21. Nikiforov YE: RET/PTC rearrangement in thyroid tumors. Endocr Pathol 13: 3-16, 2002.

22. Prescott JD and Zeiger MA: The RET oncogene in papillary thyroid carcinoma. Cancer 121: 2137-2146, 2015.

23. Thanos D and Maniatis T: NF-kappa B: A lesson in family values. Cell 80: 529-532, 1995
24. Amit S and Ben-Neriah Y: NF-kappaB activation in cancer: A challenge for ubiquitination- and proteasome-based therapeutic approach. Semin Cancer Biol 13: 15-28, 2003.

25. Aggarwal BB: Nuclear factor-kappaB: The enemy within. Cancer Cell 6: 203-208, 2004

26. Gupta SC, Sundaram C, Reuter S and Aggarwal BB: Inhibiting $\mathrm{NF}-\kappa \mathrm{B}$ activation by small molecules as a therapeutic strategy. Biochim Biophys Acta 1799: 775-787, 2010.

27. Uwagawa $T$ and Yanaga $K$ : Effect of $N F-\kappa B$ inhibition on chemoresistance in biliary-pancreatic cancer. Surg Today 45: 1481-1488, 2015.

(i) (9) This work is licensed under a Creative Commons

EY NG ND Attribution-NonCommercial-NoDerivatives 4.0 International (CC BY-NC-ND 4.0) License. 